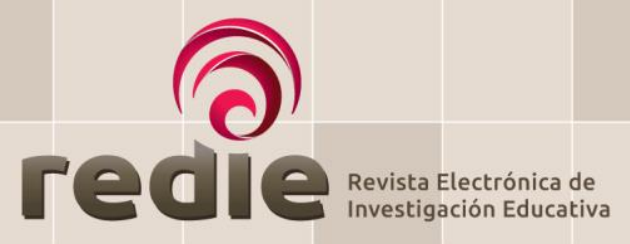

ISSN: $1607-4041$

https://redie.uabc.mx

Vol. 24, 2022/e1r

\title{
La educación como catalizador de desarrollo social
}

Ígor Mella Núñez (*) https://orcid.org/0000-0003-0189-4619

(*) Universidad de Santiago de Compostela

Cómo citar: Mella, I. (2022). La educación como catalizador de desarrollo social. Revista Electrónica de Investigación Educativa, 24, e1r, 1-2. https://doi.org/10.24320/redie.2022.24.e1r.4732

\section{Obra reseñada:}

Santos Rego, M. A. (Ed.)(2020). La transferencia de conocimiento en educación. Un desafío estratégico. Narcea, $232 \mathrm{pp}$.

En un momento como el actual, donde el vertiginoso avance y la transformación social se han visto agravados por la peor pandemia en los últimos cien años, la universidad ha de tomar como prioritaria la función de contribuir a salvaguardar el bienestar y el progreso de pueblos y sociedades. Esta coyuntura no es ajena al ámbito de las ciencias de la educación, pues el conocimiento pedagógico también importa (y mucho) en su dimensión de catalizador de desarrollo social y comunitario.

Tal vez por ello la obra que aquí se presenta nace en un momento más que oportuno, a comienzos del 2020, y en los albores de la que puede ser considerada una crisis social que, por su naturaleza y alcance, no encuentra precedentes inmediatos. Se trata, asimismo, de un contexto marcado por la incertidumbre y la necesidad de referentes rigurosos, donde el conocimiento que se genera en la investigación universitaria ha de buscar canales que lo hagan operativo en las dinámicas y situaciones cotidianas. Se trata, en suma, de dotar de funcionalidad a los saberes especializados que se construyen en la Academia, como alma mater de las diferentes sociedades, a fin de que terminen contribuyendo a la mejora de la calidad de vida.

Pero esta dimensión de la actividad universitaria discurre por senderos bien dispares en función de los diferentes campos del saber. Tal vez sea éste el motivo que empuja al profesor Santos Rego a modular una obra como la que aquí se presenta al lector, pues como bien indica en su introducción: "Muchas son, desde luego, las cuestiones que permanecen abiertas en torno a la transferencia de conocimiento. Necesitamos, pues, una posición aceptable -amén de consensuada- en y desde la educación".

Así pues, este manual reúne una serie de trabajos que se vinculan al buen quehacer de la Red de Excelencia "Universidad, Innovación y Aprendizaje en la Sociedad del Conocimiento", financiada por el Ministerio de Ciencia e Innovación español. En concreto, a lo largo de sus 11 capítulos (a los que se suma la introducción del propio Santos Rego y un epílogo a cargo del profesor Gonzalo Vázquez Gómez) se presentan teorías, modelos y experiencias que abordan la transferencia de conocimiento en el ámbito de la educación, siempre bajo la firme creencia de que dicha transferencia es conditio sine qua non para hablar de innovación o cambio educativo. En este sentido, una de las principales fortalezas del libro es su análisis integral sobre la realidad que lo motiva, pues se amalgaman las bases teóricas sobre transferencia de conocimiento con su propia praxis a partir de proyectos de alcance. Es así como se conforma una primera parte, de naturaleza teórica, y una segunda sobre la pragmática de la transferencia de conocimiento en educación.

Los primeros capítulos incluyen aportaciones y reflexiones de corte epistemológico, donde sin dejar de lado el debate conceptual en torno al propio término se presentan cuestiones como el modelo que defiende al respecto la Conferencia de Rectores de las Universidades Españolas, o el paradigma de 
cuádruple hélice, en el que a las tradicionales relaciones entre universidad, industria y gobierno se suma la propia sociedad civil, a fin de estrechar la conexión entre innovación y sociedad.

Esta primera parte se ve enriquecida con análisis orientados al ámbito de la educación. Se repara así en la pertinencia de transferir el conocimiento que genera la investigación educativa, dotándolo de significatividad y valor social, cultural -e incluso económico. Lo que se consigue en esta sección del libro es, en resumidas cuentas, arrojar luz sobre la naturaleza y los mecanismos que definen a la transferencia de conocimiento que se realiza desde la universidad al sector educativo, sin perder de vista el interés social que ha de definir a la investigación en ciencias de la educación.

Por otro lado, el segundo bloque del libro ilustra al lector sobre los principios y modelos teóricos anteriormente abordados a través de la descripción de experiencias concretas que, desde proyectos de investigación, han generado conocimiento directamente conectado con el entorno educativo y comunitario. Se trata de propuestas, desarrolladas en el marco de diferentes universidades españolas, que narran iniciativas en esferas como el aprendizaje cívico, la educación inclusiva o la acción comunitaria local.

En definitiva, estamos ante una obra más que pertinente en el momento actual, donde la incerteza reclama de claridad epistémica y procedimental en cuanto a estrategias de innovación que permitan a la sociedad civil avanzar con paso firme. Pero su potencial no sólo radica en la conveniencia temporal, sino en la claridad con que determina principios teóricos, modelos, procesos y experiencias sobre la transferencia del conocimiento que se genera por medio de la investigación educativa, tratando así de alumbrar un tema reconocidamente complejo, como es la aplicabilidad final que ha de tener el conocimiento pedagógico para incidir en el progreso y bienestar social. 